\title{
Nodular Cutaneous Amyloidosis Resembling a Giant Tumor
}

\author{
Sonja Haverkampf ${ }^{a} \quad$ Katja Evert $^{b} \quad$ Josef Schröder $^{b} \quad$ Stephan Schreml $^{a}$ \\ ${ }^{\mathrm{a}}$ Department of Dermatology, University Medical Center Regensburg, and ${ }^{\mathrm{b}}$ Institute of \\ Pathology, University of Regensburg, Regensburg, Germany
}

\section{Key Words}

Amyloid · Amyloidosis · Nodular primary localized cutaneous amyloidosis

\begin{abstract}
A 79-year-old man presented with a large tumor on the left side of his head, which had grown over 5 years. Regional lymph nodes were impalpable and computed tomography revealed no signs of bone infiltration. Histology showed that the entire dermis was filled with amorphous eosinophilic material. Immunohistochemistry was negative for cytokeratin, but showed that the dermis and parts of the subcutis were filled with amyloid consisting of immunoglobulin light chains. There were no signs of paraproteinemia or underlying plasmocytoma. In electron microscopy, the typical amyloid fibrils were found. The tumor was completely removed via curettage. At 1-year follow-up, the patient was doing fine with no signs of relapse or systemic disease.

\section{Introduction}

There are basically three variants of primary localized cutaneous amyloidosis (PLCA): macular, papular (lichenoid) and nodular forms [1-3]. In macular and papular PLCA, cytokeratins serve as the amyloid precursors, and these variants are limited to the dermis [1-4]. In contrast, the rare type of nodular PLCA originates from immunoglobulin light chains; it may extend to the subcutaneous tissue, and blood vessel infiltration can also be observed [1-3, 5]. Furthermore, nodular PLCA can originate from systemic amyloidoses or progress to systemic disease [2]. Here, we present a rare case of nodular PLCA, which resembled a giant tumor on the head.

\section{KARGER}

Stephan Schreml, MD, PhD

Department of Dermatology, University Medical Center Regensburg

Franz-Josef-Strauss-Allee 11

DE-93053 Regensburg (Germany)

E-Mail stephan@schreml.de 


\section{Case Report}

A 79-year-old man presented with a large tumor on the left side of his head (fig. 1a), which had grown over 5 years. The waxy tumor exhibited a sulcated, mostly yellowish and reddish surface, and in some areas hemorrhages. Regional lymph nodes were impalpable. Computed tomography revealed no signs of bone infiltration. A punch biopsy showed amorphous eosinophilic material in the dermis, so that we suspected a giant amyloid tumor $[1,2$, 4]. The tumor was completely removed via curettage (fig. 2). Histology showed that nearly the entire dermis was filled with amorphous eosinophilic material (fig. 1b), and these masses extended down to the subcutis. Immunohistochemistry was negative for cytokeratin, but showed that the entire dermis and parts of the subcutis were filled with amyloid consisting of both kappa and lambda immunoglobulin light chains (fig. 1c, d) [5, 6]. There were no signs of paraproteinemia or underlying plasmocytoma. In electron microscopy, the typical amyloid fibrils (7-10 nm in diameter) were found (fig. 1e) [2]. To rule out systemic amyloidosis, we performed fine-needle abdominal fat aspiration, and the samples showed only minimal traces of amyloid, thus no signs of systemic amyloidosis [6]. Therefore, the diagnosis was primary localized cutaneous nodular light chain amyloidosis. At 1-year follow-up, the patient was doing fine with no signs of relapse. However, he will be screened regularly for possible progress to systemic disease.

\section{Discussion}

The diagnosis of PLCA requires histological analysis of a skin specimen. In order to discriminate the amyloid precursors in PLCA, immunohistochemistry with antibodies against cytokeratin and immunoglobulin light chains (lambda and kappa subtypes) should be done. It is best to also use electron microscopic work-up of a sample fixed in Karnofsky's fixative (glutaraldehyde). As amyloid fibrils are quite stable, electron microscopy can also be done from formalin-fixed samples; however, image quality will be reduced with this standard fixative. The typical amyloid fibrils with diameters of 7-10 nm definitely confirm the diagnosis of amyloidosis. Nodular PLCA can often be successfully treated surgically, e.g. via curettage, excision or ablative laser therapy $\left(\mathrm{CO}_{2}\right.$ lasers etc.). Patients should regularly be screened for progression to systemic disease as this may occur in $5-50 \%$ of cases [2]. To do so, a full history and physical examination along with an electrocardiogram, complete blood count, serum creatinine level, serum liver-associated enzymes levels, serum protein electrophoresis and urine protein electrophoresis should be preformed [3]. It has also been suggested that an abdominal fat biopsy (easy access for screening) be performed to rule out systemic disease [6]. To our knowledge, this is the most extensive case of nodular PLCA reported in the literature.

\section{Statement of Ethics}

Written informed consent to publish the images was obtained from the patient.

\section{Disclosure Statement}

The authors have no conflict of interest. 


\section{Case Reports in Dermatology}

\begin{tabular}{l|l}
\hline Case Rep Dermatol 2016;8:22-25 \\
\hline DOI: $10.1159 / 000443950$ & $\begin{array}{l}\text { (c) 2016 The Author(s). Published by S. Karger AG, Basel } \\
\text { www.karger.com/cde }\end{array}$ \\
\hline
\end{tabular}

Haverkampf et al.: Nodular Cutaneous Amyloidosis Resembling a Giant Tumor

\section{References}

1 Breathnach SM: Amyloid and amyloidosis. J Am Acad Dermatol 1988;18:1-16.

-2 Schreml S, Szeimies RM, Vogt T, Landthaler M, Schroeder J, Babilas P: Cutaneous amyloidoses and systemic amyloidoses with cutaneous involvement. Eur J Dermatol 2010;20:152-160.

3 Schreml S: Cutaneous amyloidoses; in Griffiths C, Barker J, Bleiker T, Chalmers R, Creamer D (eds): Rook's Textbook of Dermatology, 9th edition. John Wiley and Sons, 2016, chapter 58.

4 Brownstein MH, Helwig EB: The cutaneous amyloidoses. I. Localized forms. Arch Dermatol 1970;102:8-19.

5 Ritchie SA, Beachkofsky T, Schreml S, Gaspari A, Hivnor CM: Primary localized cutaneous nodular amyloidosis of the feet: a case report and review of the literature. Cutis 2014;93:89-94.

-6 Westermark P, Davey E, Lindbom K, Enqvist S: Subcutaneous fat tissue for diagnosis and studies of systemic amyloidosis. Acta Histochem 2006;108:209-213.

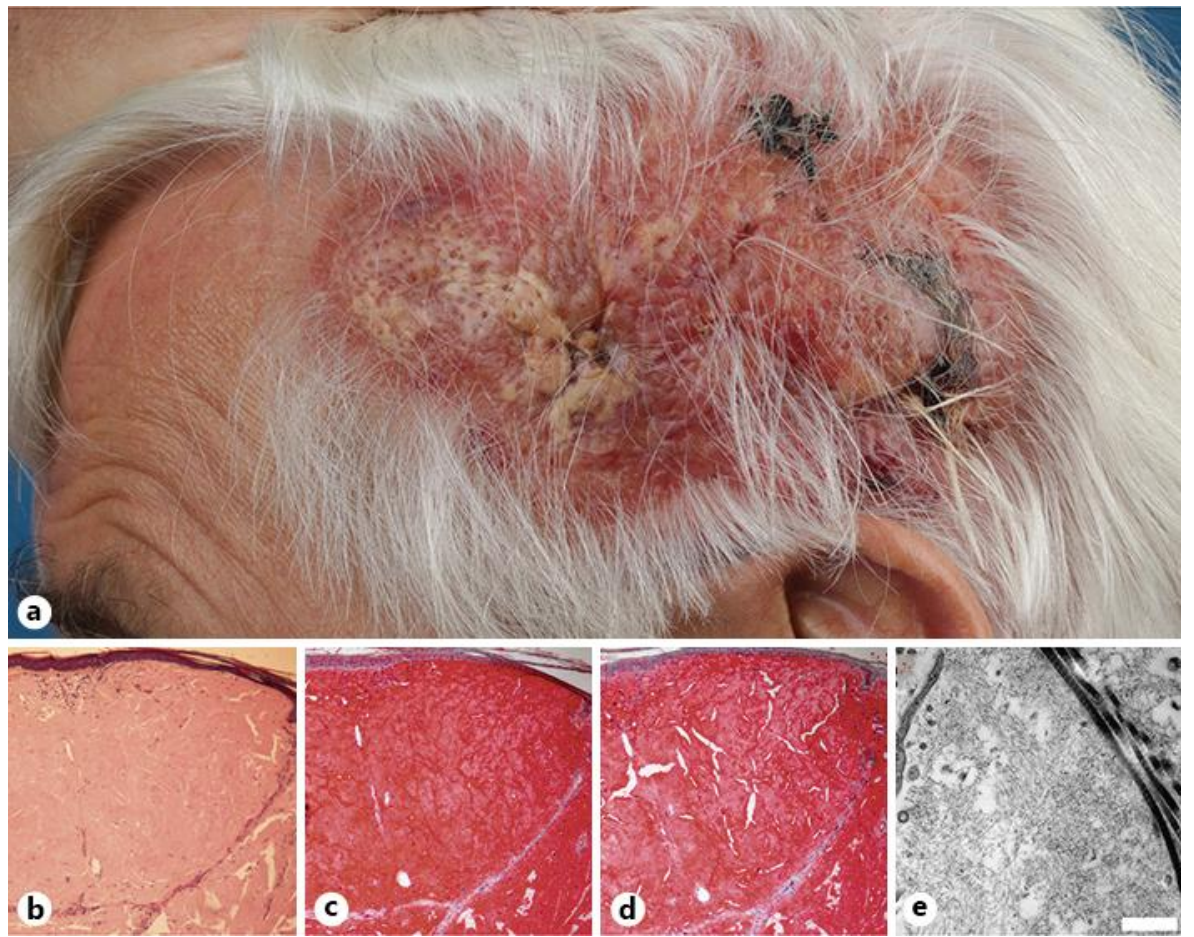

Fig. 1. a Large tumor on the left side of the head (male, 79 years). b-d The waxy tumor exhibited a sulcated, mostly yellowish and reddish surface, and in some areas hemorrhages. A punch biopsy showed amorphous eosinophilic material in the dermis (b), and these masses extended down to the subcutis. Immunohistochemistry showed that the entire dermis and parts of the subcutis were filled with amyloid consisting of both kappa and lambda immunoglobulin light chains (c, d). e In electron microscopy, the typical amyloid fibrils (7-10 $\mathrm{nm}$ in diameter) were found (bar $=0.5 \mu \mathrm{m}$ ). 


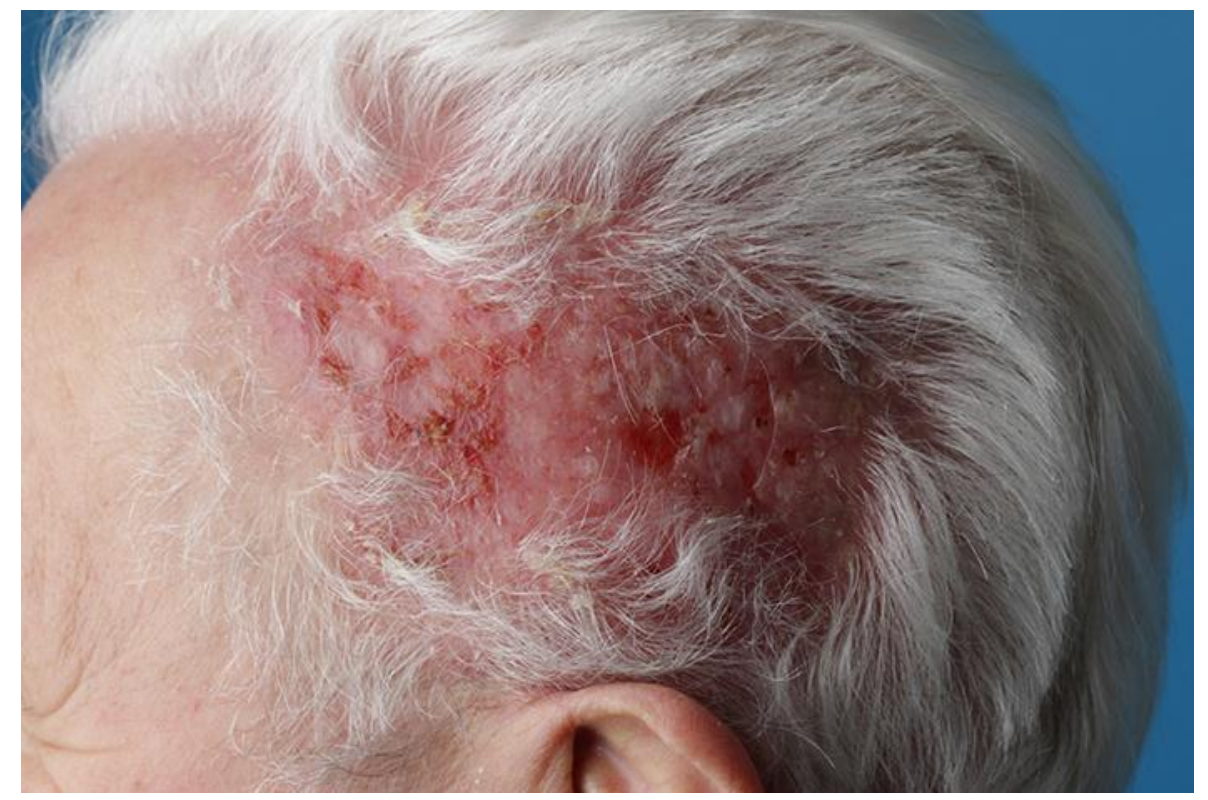

Fig. 2. The patient at follow-up 1 month after surgery. He showed no signs of local tumor recurrence or systemic disease. 